\title{
NORMAL INCIDENCE SOUND ABSORPTION COEFFICIENT OF DIRECT PIERCING CARVED WOOD PANEL WITH DAUN SIREH MOTIF USING BOUNDARY ELEMENT METHOD
}

\section{Mohd Zamri Jusoh ${ }^{1, ~ a, ~ M o h a m a d ~ N g a s r i ~ D i m o n ~}{ }^{2, b}$, You Kok Yeow ${ }^{2, c}$, Nazli Che Din $^{3}$ and Rafidah Rosman ${ }^{4}$}

\author{
${ }^{1}$ Faculty of Electrical Engineering, Universiti Teknologi MARA(Terengganu), \\ Sura Hujung, 23000 Dungun,Terengganu, Malaysia. \\ amohdz530@tganu.uitm.edu.my \\ Phone:+6098403967;Fax:+6098403777 \\ ${ }^{2}$ Communication Engineering Department, Faculty of Electrical Engineering, \\ Universiti Teknologi Malaysia, 81310 Skudai, Johor, Malaysia. \\ bngasri@fke.utm.my, ${ }^{\mathrm{c}}$ kyyou@fke.utm.my \\ ${ }^{3}$ Department of Architecture, Faculty of Built Engineering, University of Malaya, \\ 50603, Kuala Lumpur, Malaysia \\ ${ }^{4}$ Faculty of Electrical Engineering, Universiti Teknologi MARA(UiTM), \\ 40450 Shah Alam, Selangor, Malaysia.
}

\begin{abstract}
The Direct Piercing Carved Wood Panel (DPCWP) installed in Masjid Abidin, Kuala Terengganu, is one example that carries much aesthetic and artistic value. The use of DPCWP in earlier mosques was envisaged to improve the intelligibility of indoor speech because the perforated panels allow some of the sound energy to pass through. In this paper, the normal incidence sound absorption coefficient of DPCWP with Daun Sireh motif, which is a form of floral pattern, is discussed. The Daun Sireh motif was chosen and investigated for 30\%, 35\%, 40\%, and $45 \%$ perforation ratios. The simulations were conducted using BEASY Acoustic Software based on the boundary element method. The simulation results were compared with measurements obtained by using the sound intensity technique. An accompanying discussion on both the numerical and the measurement tendencies of the sound absorption characteristics of the DPCWP is provided. The results show that the DPCWP with Daun Sireh motif can act as a good sound absorber.
\end{abstract}

Keywords: Normal incidence; sound absorption coefficient; DPCWP; BEM.

\section{INTRODUCTION}

A direct piercing carved wood panel (DPCWP) with floral pattern is one of the famous shapes and styles of wood carving in Malaysia (Nordin, 2009). This pattern was embedded in Malay wood carving several hundred years ago. Nowadays, this pattern is still popular as a style selected for wood carved panels used as parts of mosques and wall panels in traditional Malay houses (Ismail, 1986; Azmi Ngah, 1991; Said, 2001; Said and Kamarudin, 2009; Sahrif, 2010). The DPCWP with floral pattern is very beautiful and meaningful because it comes from the expression of Malay wood carvers, based on the surrounding floral elements in their lives. However, the wood carvers may use their own creativity to generate intricate floral elements in their product. While numerous studies have been proposed to measure the sound absorption coefficient 
(SAC) of DPCWP (Ula, 2006; Dimon, 2009a), the databases for DPCWP with floral pattern are still inadequate. The investigation and estimation of the SAC of perforated panels has become an important topic in acoustic research (Lin et al., 2008); hence, it is important to investigate the SAC of the DPCWP with floral pattern. One of the difficulties in measuring the SAC of DPCWPs using experimental methods is that the properties of the DPCWPs change with the environment (Dimon et al., 1997). Accordingly, owing to the complexity of the floral pattern, the boundary element method (BEM) is the main tool used for studying the SAC of DPCWPs in this study, because it is efficient both in terms of both computer time and of storage (Fenner, 1983). Thus, a sample from one of the oldest mosques in Malaysia was taken for the SAC performance study. In the first section of this paper, we review briefly the DPCWP sample used for our simulation and measurement work. In the next section, the simulation and measurement processes are discussed and finally, the simulation results obtained from the numerical method are compared with the measurement results.

\section{DPCWP with Daun Sireh Motif}

The selected DPCWP in our work was installed at the right wall partition of Masjid Abidin (MA) located in Kuala Terengganu, Terengganu. This DPCWP is based on the Daun Sireh motif (DSM), which can be found in each of the door leaves. It is believed that the DPCWP were designed and installed during the governance of Sultan Zainal Abidin III in 1901, and carved by two popular Malay wood carvers, Tengku Abdul Kadir Salim and Haji Abdul Rahman Instanbul (Haji Awang, 1983). There are four door leaves for each door panel and there are seven door panels installed along the wall. Each of the door leaves comprises two DPCWPs with DSM at the upper partition of the door leave. Each DPCWP with DSM consists of six complete Daun Sireh patterns, which are arranged inversely to each other, as shown in Figure 1. The DPCWP with DSM was chosen because it is the most common pattern in the mosque. The dimensions of each DPCWP with DSM are $0.367 \times 0.629 \mathrm{~m}$. It was also observed that for each DPCWP with DSM, a single pattern is repeated and combined together to complete a full DPCWP. The measured DPCWP with DSM at MA has a perforation ratio of $28 \%$. However, owing to periodic conservation processes, the DPCWP is covered with duck egg's shell flour, which causes a decrement in the perforation ratio of the entire panel. The design was transferred to CAD software for the processes of redrawing and calculating the perforation ratio, as shown in Figure 2. Then, the data retrieved from the CAD software were transferred to BEASY acoustic software for the modeling and simulation process. The perforation ratio was set to $30 \%, 35 \%, 40 \%$, and $45 \%$. These ratios were selected based on the effectiveness of the DPCWP with DSM and represent a typical range of perforation ratios normally adopted by the wood carvers. Might it be that perforation ratios below 30\% would not offer the desired acoustic effect and that perforation ratios above $45 \%$ affect the stability or integrity of the wall panel? 


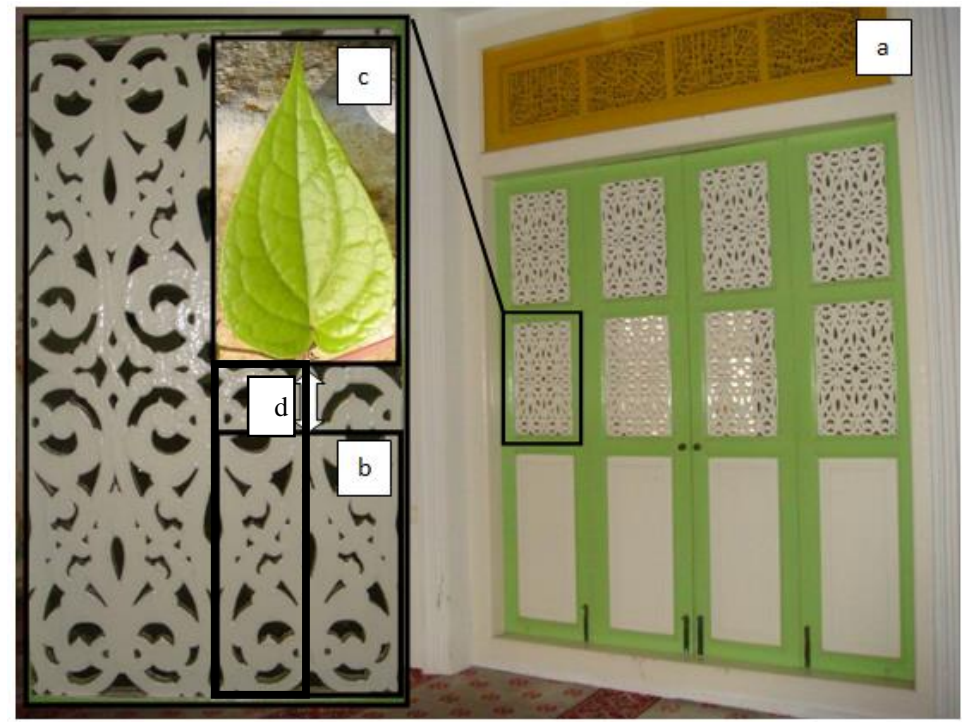

Figure 1. DPCWP with floral motives: (a) door panel in MA, (b) Daun Sireh pattern, (c) Daun Sireh, and (d) single pattern.

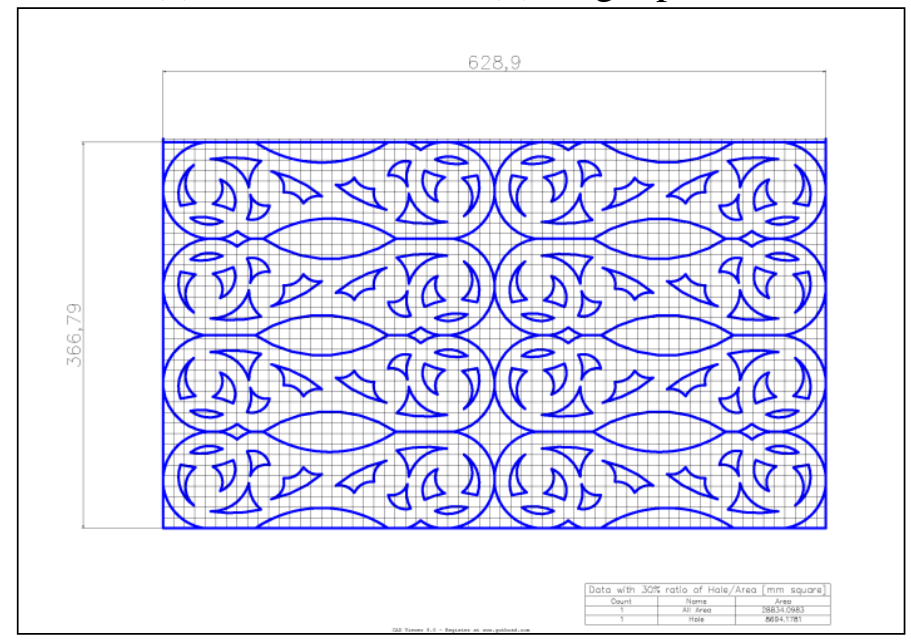

Figure 2. DPCWP design using CAD.

\section{SIMULATION METHOD}

The modeling process was done by using one-quarter size of the actual size of the pattern, which is practical because it reduces the simulation time. The sound absorption coefficient $\left(\alpha_{n}\right)$ was calculated by dividing the net sound intensity value in front of the circular panel with the incident sound intensity obtained in an empty room. The modeling process started with the creation of the anechoic room with the panel, and continued with the creation of the anechoic room without the panel. All measurements and coordinates used in the BEASY Acoustic software were in meters $(\mathrm{m})$. The dimensions of a single pattern of the DPCWP with DSM are 0.0917-m high and 0.3145$\mathrm{m}$ wide. The ideal DPCWP dimensions for simulation purposes are projected to a height of $1.152 \mathrm{~m}$, a width of $1.256 \mathrm{~m}$ and a thickness of $0.02 \mathrm{~m}$, which contains 4 rows and 12 columns in the $y-z$ dimension. However, actual modeling for the simulation work required the one-quarter modeling approach; therefore, the DPCWP dimensions were reduced to a height of $0.576 \mathrm{~m}$ and a width of $0.629 \mathrm{~m}$, which translated to two rows 
and six columns of a single pattern. The framework of this model was begun by identifying the coordinates of the first lower aperture using CAD software. The design was completed by creating its points, lines and patches. After the first lower aperture was created, the formation of the basic design of the floral pattern was performed by copying the lower aperture to the upper side, as a fundamental of the entire panel arrangement. The rest of the floral panel was created by copying and transforming the basic floral design to the right and upper side. The completed panel for simulation was simulated using BEASY, and consisted of a combination of 12 single patterns, as shown in Figure 3. For a single pattern of the DPCWP with DSM, 100 points were created. The number of patches created for a single pattern was 48 for a three dimensional DPCWP with DSM. Then, the single pattern was repeated inversely giving 12 single patterns with 576 patches. The thickness of the patch is $20 \mathrm{~mm}$. One quarter of the anechoic room was formed at the front side, rear side, top side and right side of the patches. The anechoic room was modeled as a free field condition by defining that the acoustic impedance of the patches is equal to the acoustic impedance of air with the volume of 1 $\mathrm{m}^{3}$. The modeling process began with the $2.1 \mathrm{~m}$ line creation at the front side of the floral panel. The distance for the back panel room from the DPCWP is $0.77 \mathrm{~m}$. Based on our parametric study (Dimon et al., 2009c), one-quarter size of the DPCWP with DSM is sufficient to investigate the SAC performance. Figure 4 shows the complete quarter size anechoic room with DPCWP with DSM.

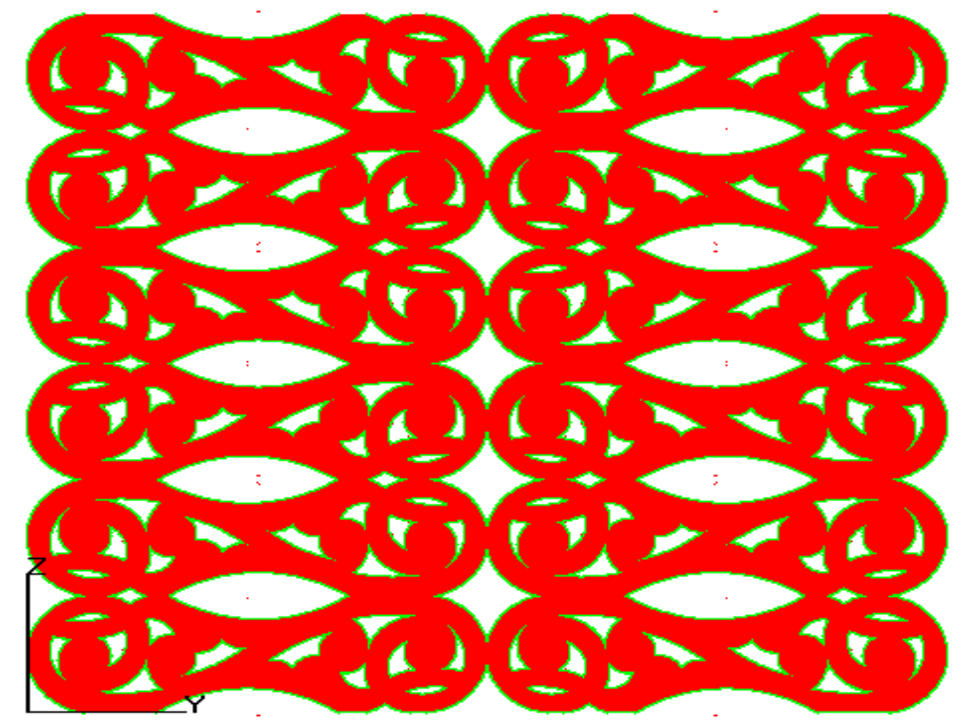

Figure 3. Completed panel for simulation by using BEASY.

During the simulation, the following material properties were used: air density, $1.21 \mathrm{Kgm}^{-3}$; speed of sound, $340 \mathrm{~ms}^{-1}$; and reference pressure, $2.0 \times 10^{-5} \mathrm{~Pa}$. The impedances for the patches of DPCWP and the anechoic room were $3.366 \times 10^{6} \mathrm{kgm}^{-2} \mathrm{~s}^{-}$ ${ }^{1}$ and $415 \mathrm{kgm}^{-2} \mathrm{~s}^{-1}$, respectively. Up to 155 internal points were used with each internal point located at the middle and in front of each aperture. The distances of the internal points from the surface were $0.34,0.17,0.085,0.0425$, and $0.10625 \mathrm{~m}$ for $250 \mathrm{~Hz}, 500$ $\mathrm{Hz}, 1 \mathrm{kHz}, 2 \mathrm{kHz}$, and $4 \mathrm{kHz}$, respectively. All distances refer to the 0.25 sound wavelength $(\lambda)$ of each frequency, except for $4 \mathrm{kHz}$, because the distance was too close to the surface and thus, the distance was adjusted to $1.25 \lambda$. The distances were chosen to correspond with former measurement techniques conducted in anechoic chambers 
(Dimon, 2002; Dimon, 2006; Dimon, 2009b). The sound pressure level was set to $0.25 \lambda$ to minimize the error in obtaining sound intensity values. The sound source was represented by a point source of strength $0.0005 \mathrm{~Pa} / \mathrm{m}$ positioned at diagonal center, $2 \mathrm{~m}$ in front of the DPCWP patches.

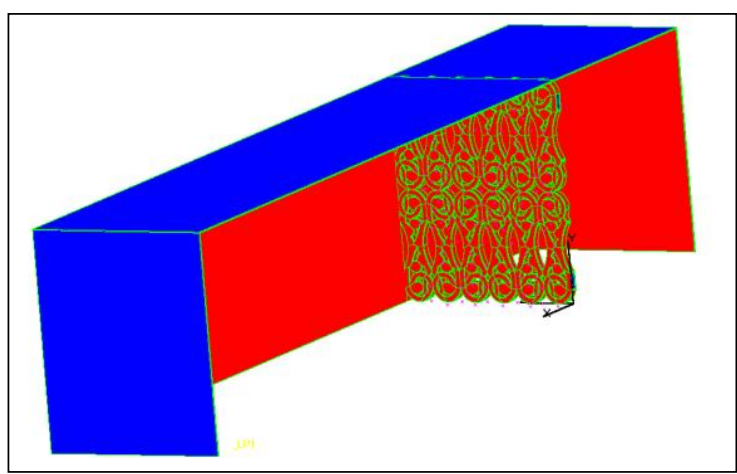

(a)

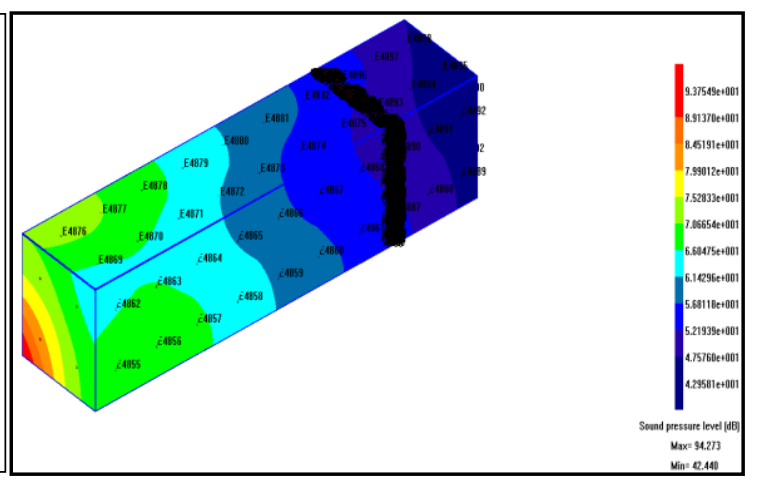

(b)

Figure 4. DPCWP with DSM by using BEASY: (a) Quarter size room with panel, and (b) sound pressure level in the room during simulation process.

\section{SOUND INTENSITY METHOD}

The sound intensity technique has been developed and used widely to investigate the sound power and SAC for such materials, and is based on the sound energy density and active intensity. There are numerous methods for implementing the sound intensity technique, but the most popular method is to measure the sound power and SAC of materials by using a p-p probe to measure the flow of the active intensity on the material's surface. The intensity reference level, the selection of the microphone spacer between the p-p probe, the sampling type, and the measurement distance are the parameters that need to be taken into consideration for the sound intensity measurement.

For sound intensity, the reference level is:

$$
I_{0}=1 \times 10^{-12} \mathrm{~W} / \mathrm{m}^{2}
$$

The most suitable microphone spacer to measure the sound intensity for the DPCWP is $12 \mathrm{~mm}$ (Gade, 1985; Lai and Burgess, 1991; Farina and Torelli, 1997; Jacobsen, 1997). The selection of microphone spacer is based on measurement frequencies and the distance for reproducing the settings of the $30 \%$ and $40 \%$ perforation ratios in the simulation method. 16 points were selected by using the point sampling method and these are focused at the middle of the DPCWP. The size of the DPCWP for the sound intensity measurement is $1.2 \times 1.2 \mathrm{~m}$ with 20 -mm thickness. Each point took 20 seconds to complete the individual measurement using the 3595 B\&K Sound Intensity p-p probe. The probe was connected to a B\&K Type 2260-E Investigator and the B\&K Type 4224 sound source was employed to radiate the noise. A customized frame with a grid of ropes was located in front of the DPCWP to guide the probe to the exact location during the measurements, as shown in Figure 5. 


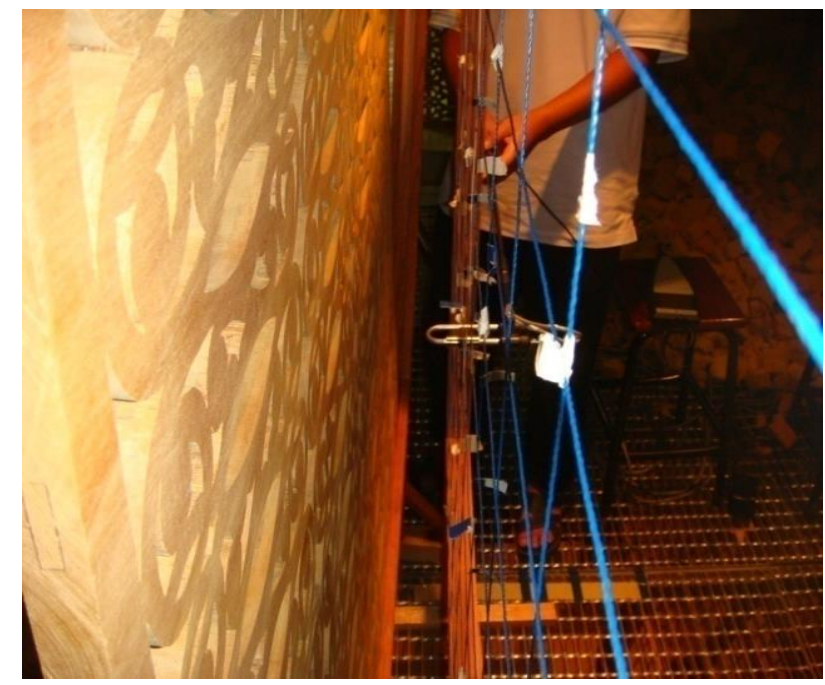

Figure 5. P-P probe during sound intensity measurement.

\section{RESULTS AND DISCUSSION}

The simulated values of $\alpha_{n}$ are tabulated in Table 1 and the decay trend from $250 \mathrm{~Hz}$ to $4 \mathrm{kHz}$ for 30\%, 35\%, 40\%, and 45\% perforation ratios are illustrated in Figures 6 and 7. From the figures, $\alpha_{n}$ has a smooth decrement from $250 \mathrm{~Hz}$ to $1 \mathrm{kHz}$. The paper reveals that at low frequencies, the thickness of the carved wood panel plays an important role in determining the value of $\alpha_{n}$. Furthermore, low frequencies (or large wavelengths) will penetrate the carved wood panel that has a certain thickness and cause the value of $\alpha_{n}$ for the carved wood to change with frequency. At frequencies exceeding $1 \mathrm{kHz}$, the value of $\alpha_{n}$ remains constant with frequency. Clearly, the determination of $\alpha_{n}$ for carved wood that has a thickness of $0.02 \mathrm{~m}$ requires more than $1 \mathrm{kHz}$ operating frequency when using the measurement system of this study. Overall, the carved wood panel with a $45 \%$ perforation ratio has a higher absorption coefficient than the panel with a $30 \%$ perforation ratio, which suggests that the DPCWP with a greater perforated area has better SAC performance. However, at $2 \mathrm{kHz}$, there are small increments of $\alpha_{n}$ for $35 \%$ and $40 \%$ perforation ratios. For $35 \%, 40 \%$, and $45 \%$ perforation ratios, from 1 $\mathrm{kHz}$ to $2 \mathrm{kHz}, \alpha_{n}$ differs within \pm 0.02 and this suggests that the SAC has not changed significantly for better or for worse. The results show that at higher frequency $\alpha_{n}$ is similar for $40 \%$ and $45 \%$ perforation ratios. The comparison suggests that all perforation ratios have better $\alpha_{n}$ at lower frequency. At $250 \mathrm{~Hz}$ and $500 \mathrm{~Hz}$, the $\alpha_{n}$ results are the highest, which is similar compared with our previous work (Dimon et al., 2010). Further statistical analysis was performed to determine the rate of relative error of the approximation of the SAC performance based on the BEM results. All results show low relative error $(<2.5 \%)$ that explains the consistencies of the modeling and simulation work during the merging and meshing processes.

The normal incidence SACs $\alpha_{n}$ for $30 \%$ and $40 \%$ perforation ratios obtained from the measurement work are presented in Table 2 and Figure 8. The values of $\alpha_{n}$ for both $30 \%$ and $40 \%$ perforation ratios demonstrate a basic tendency from 250 to $500 \mathrm{~Hz}$ and almost a flat trend from 1 to $4 \mathrm{kHz}$. A comparison between the simulation and experimental results, tabulated in Table 3, shows that $\alpha_{n}$ is correlated closely and proves the reliability of the BEM approach for investigating the SAC of DPCWPs with floral patterns. A further observation can be stated as the discrepancies can be 
considered as having the dissimilarity of setting between the numerical and experimental work. In this research, using the numerical method, the $\alpha_{n}$ value was investigated based on the surface of the DPCWP panel. The $\alpha_{n}$ value was gained using an internal point located at the middle of each aperture. However, the sound intensity technique allows that a certain area on the surface of the DPCWP can be investigated to gain the $\alpha_{n}$ value during the near-field measurement process. The internal points were used based on the number of apertures available for measurement, whereas there were 16 points investigated when using the sound intensity technique. However, instead of all the discrepancies, both simulations and sound intensity results show an agreement in terms of the tendency of the $\alpha_{n}$ value for most frequencies. This suggests that both results are correlated closely.

Table 1. $\alpha_{n}$ simulation results for all perforation ratios.

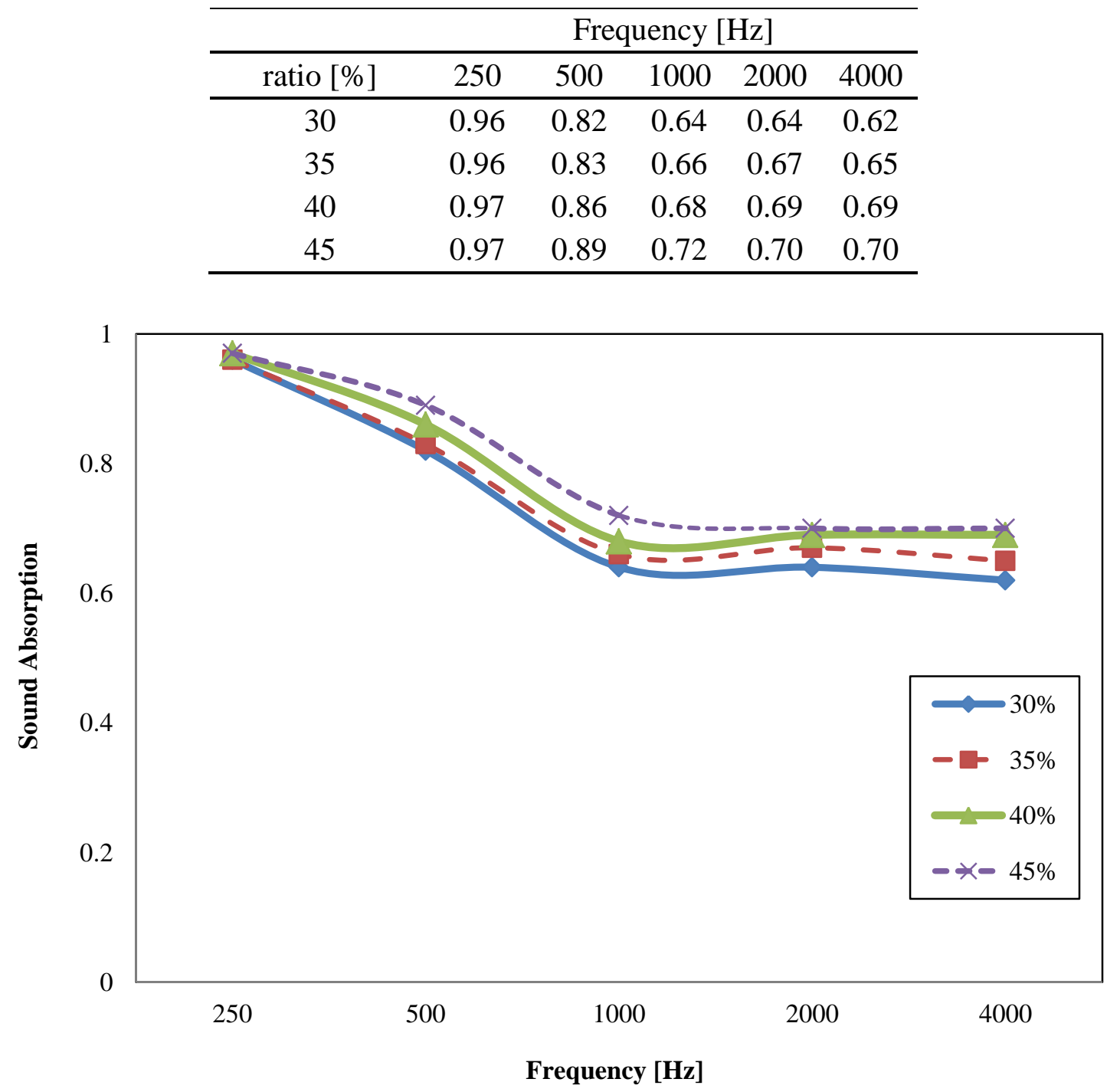

Figure 6. Simulated $\boldsymbol{\alpha}_{\boldsymbol{n}}$ performance for $30 \%, 35 \%, 40 \%$, and $45 \%$ perforation ratios. 


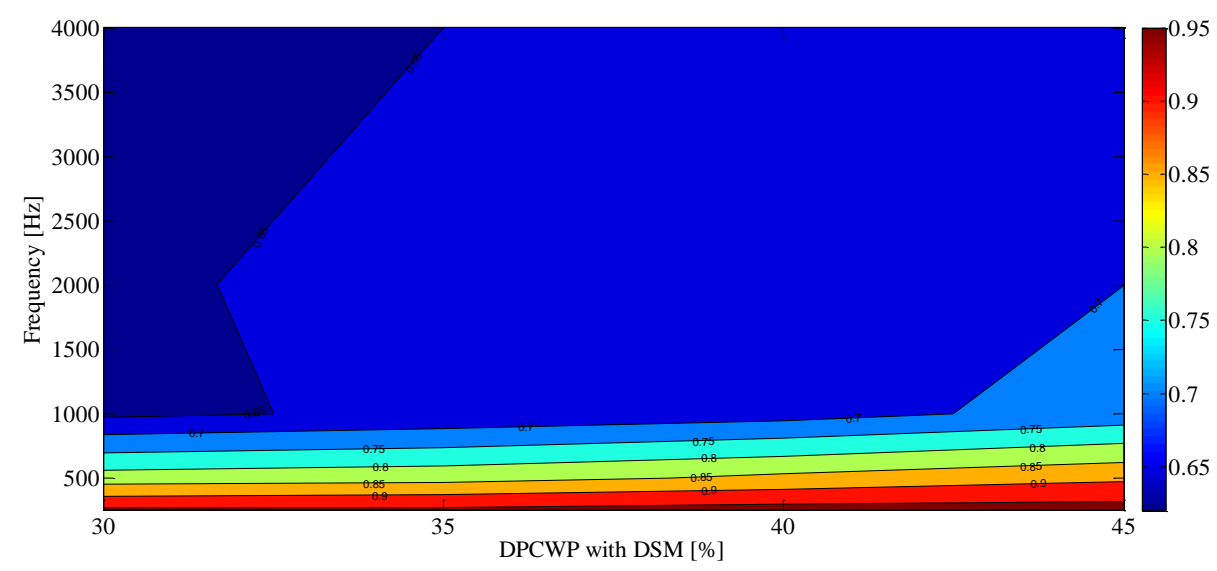

(a)

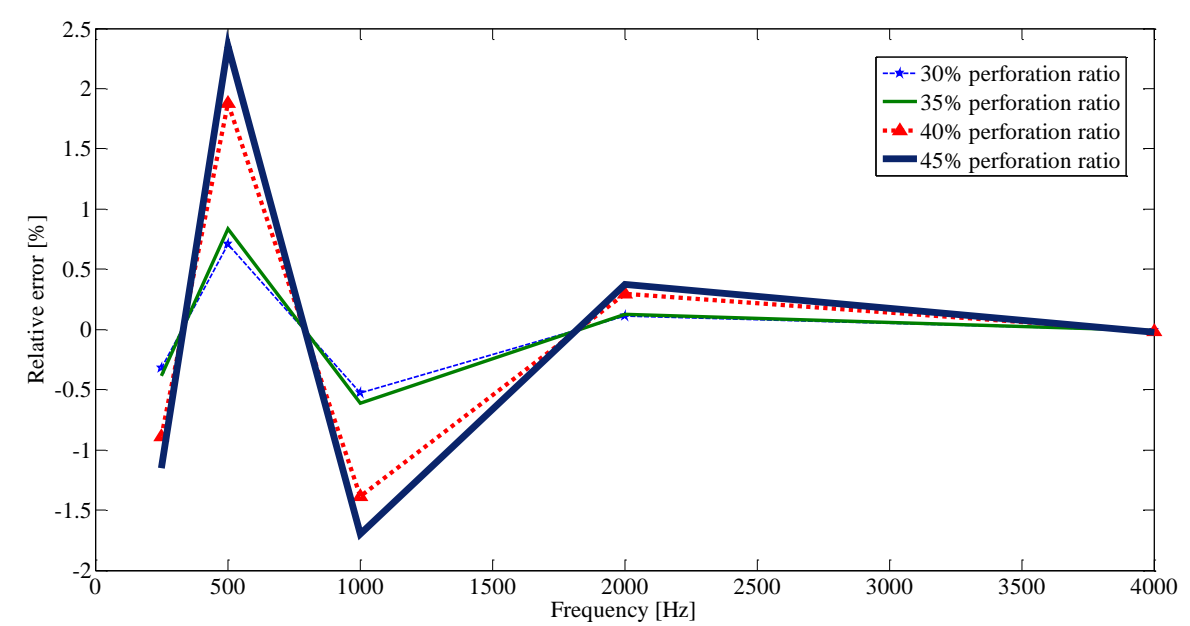

(b)

Figure 7. Simulation results for $30 \%, 35 \%, 40 \%$, and $45 \%$ per. ratios:

(a) SAC performance, and (b) relative error.

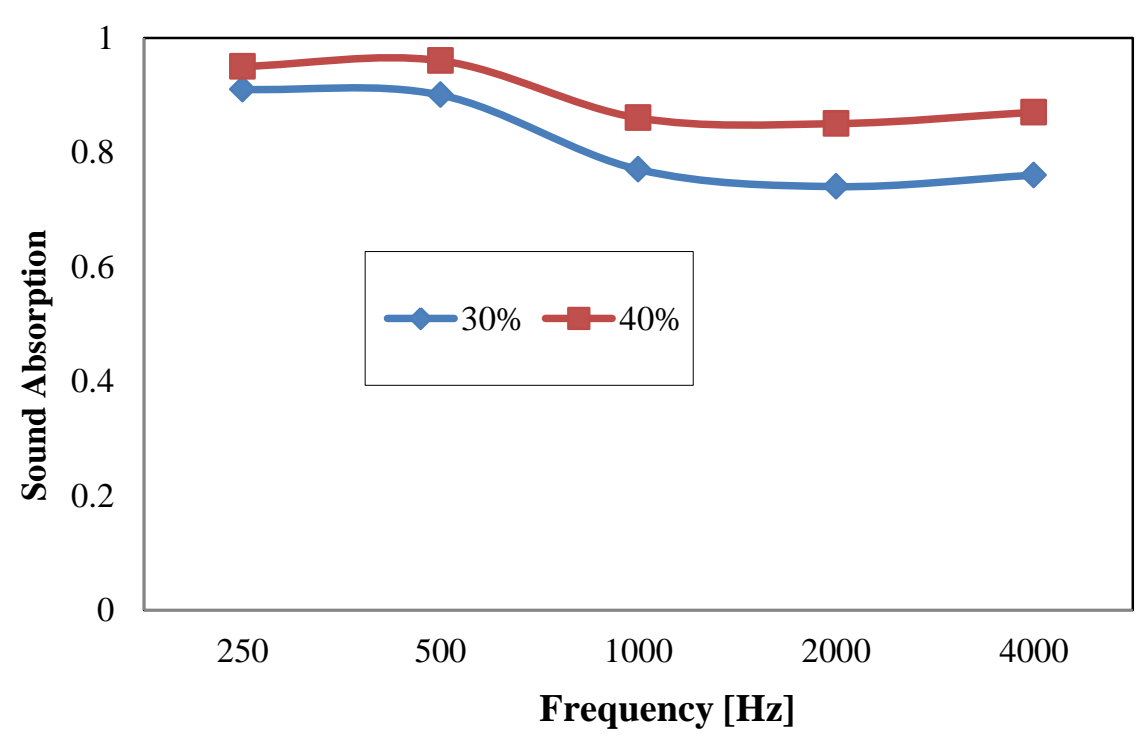

Figure 8 . Measured $\boldsymbol{\alpha}_{\boldsymbol{n}}$ performance for $30 \%$ and $40 \%$ perforation ratios. 
Table 2. $\alpha_{n}$ measurement results for $30 \%$ and $40 \%$ perforation ratios.

\begin{tabular}{cccccc}
\hline & \multicolumn{5}{c}{ Frequency $(\mathrm{Hz})$} \\
\hline ratio[\%] & 250 & 500 & 1000 & 2000 & 4000 \\
\hline 30 & 0.91 & 0.9 & 0.77 & 0.74 & 0.76 \\
40 & 0.95 & 0.96 & 0.86 & 0.85 & 0.87 \\
\hline
\end{tabular}

Table 3. $\alpha_{n}$ comparison of simulation and measurement results.

\begin{tabular}{|c|c|c|c|c|c|c|}
\hline \multirow[b]{2}{*}{ Sample } & \multicolumn{5}{|c|}{ Frequency $(\mathrm{Hz})$} & \multirow{2}{*}{ NRC } \\
\hline & 250 & 500 & 1000 & 2000 & 4000 & \\
\hline \multicolumn{7}{|c|}{$30 \%$ perforation ratio } \\
\hline Simulation results & 0.96 & 0.82 & 0.64 & 0.64 & 0.62 & 0.77 \\
\hline Sound Intensity results & 0.91 & 0.90 & 0.77 & 0.74 & 0.76 & 0.83 \\
\hline Difference & 0.05 & 0.08 & 0.13 & 0.10 & 0.14 & 0.07 \\
\hline \multicolumn{7}{|c|}{$40 \%$ perforation ratio } \\
\hline Simulation results & 0.97 & 0.86 & 0.68 & 0.69 & 0.69 & 0.80 \\
\hline Sound Intensity results & 0.95 & 0.96 & 0.86 & 0.85 & 0.87 & 0.91 \\
\hline Difference & 0.02 & 0.10 & 0.18 & 0.16 & 0.18 & 0.11 \\
\hline
\end{tabular}

\section{CONCLUSIONS}

The DPCWP with DSM at 30\%, 35\%, 40\%, and 45\% perforation ratios show the ability to absorb sound waves particularly from $250 \mathrm{~Hz}$ to $4 \mathrm{kHz}$. This is shown through the simulation results discussed earlier. The value of $\alpha_{n}$ is the highest at the lowest frequency for all perforation ratios, but decreases as the frequency increases. However, the trend of $\alpha_{n}$ is almost similar for all perforation ratios, in which the value of $\alpha_{n}$ has a smooth decrement, and at higher frequencies, from 1 to $4 \mathrm{kHz}$, the value of $\alpha_{n}$ has small deviation. Furthermore, the simulation and sound intensity results exhibit a similar trend for $\alpha_{n}$ from $250 \mathrm{~Hz}$ to $4 \mathrm{kHz}$. The trend begins with a small decrement from the lower frequency to $500 \mathrm{~Hz}$; it then shows a drastic decrement at $1 \mathrm{kHz}$, followed by a flat tendency from 1 to $4 \mathrm{kHz}$. Finally, the simulation and measurement results are correlated closely.

\section{ACKNOWLEDGMENTS}

The authors would like to acknowledge the Universiti Teknologi Malaysia for providing laboratory facilities and equipment, and the Universiti Teknologi MARA for financial assistance under project 600-RMI/ST/FRGS 5/3/Fst (30/2008).

\section{REFERENCES}

Azmi Ngah, C.M. 1991. Masjid Abidin Kuala Terengganu. Berita Darul Iman, JulyAug. p. 2.

Dimon, M.N. 2002. Normal Incidence sound transmission coefficient prediction using sound intensity technique. $\mathrm{PhD}$ Thesis, Universiti Teknologi Malaysia, Malaysia. 
Dimon, M.N. 2006. The study of normal incidence sound absorption coefficient of wood circular perforated panel (CPP) using numerical modeling technique. Universiti Teknologi Malaysia. Research report. Vot 75117.

Dimon, M.N. 2009a. Normal incidence sound absorption coefficient of direct piercing carved wood panel (DPCWP) with geometric pattern. Project Report. Faculty of Electrical Engineering, Skudai, Johor, Malaysia.

Dimon, M.N. 2009b. Normal Incidence Sound Absorption Coefficients of Direct Piercing Carved Wood Panels (DPCWP) With Geometric Pattern. Universiti Teknologi Malaysia. Research Project No. 79013.

Dimon, M.N., Adzim, S.D., Kit, M.H. and Hashim, A.W.I. 2010. Normal incidence sound absorption coefficient of direct piercing carved wood panel with star dominated geometric pattern. Proceedings of NVC. pp.62-72.

Dimon, M.N., Hashim, A.W.I., Hamid,S.Z.A. and Harun, M. 2009c. Normal incidence sound absorption coefficient of direct piercing carved wood panel with star and diamond dominated geometric pattern. Proceedings of ACOUSTICS. Adelaide. Australia.

Dimon, M.N., Singh, S., Saketar, S. and Khan, A.S. 1997. Absorption coefficient measurements using a sound intensity technique: A preliminary work. Audio Engineering Society, 102- 4408.

Farina, A. and Torelli, A. 1997. Measurement of sound absorption coefficient of materials with sound intensity technique. Audio Engineering Society. 4409.

Fenner, R.T. 1983. The boundary equation (boundary element) method in engineering stress analysis. Journal of Strain Analysis for Engineering Design, pp. 1-3.

Gade, S. 1985. Validity of intensity measurements in partially diffuse sound field. Bruel and Kjaer Technical Review, 4. pp. 3-31.

Haji Awang, M.S. 1983. Masjid Abidin Kuala Terengganu, Utusan Printcorp Sdn. Bhd. Kuala Lumpur. pp. 292-293.

Ismail, S.Z. 1986. Rekabentuk kraftangan melayu tradisi. Dewan Bahasa dan Pustaka, Kuala Lumpur.

Jacobsen, F. 1997. An overview of the source of error in sound power determine using sound intensity technique. Applied Acoustics, 50(2): 155-166.

Lai, J.C.S. and Burgess, M. 1991. Application of sound intensity technique to measure of field sound transmission loss. Applied Acoustics, 34(2): 77-87.

Lin, M.D., Tsai, K.T. and Su, B.S. 2008. Estimating the sound absorption coefficients of perforated wood panels by using ANN. Applied Acoustics, 70(1): 31-40.

Nordin, N. 2009. Ukiran Kayu Warisan Melayu. First ed., Perbadanan Kraf Malaysia.

Said, I. 2001. Art of woodcarving in timber mosques of Peninsular Malaysia and Southern Thailand. Journal of Technology, 34(B): 45-56.

Said, I. and Kamarudin, Z. 2009. Carving motives in timber houses of Kelantan and Terengganu. Proceedings of SEATUC, pp. 45-49.

Shariff, N.A. 2010. Terengganu selected handicrafts. Yayasan di Raja Sultan Mizan.

Ula, M. 2006. The study of normal incidence sound absorption coefficient of wood circular perforated panel using numerical modeling technique. Research Report, Project No. 75117, UTM, Malaysia. 